\title{
Association between coarse particulate matter and inflammatory and hemostatic markers in a cohort of midlife women
}

Emilie Davis ${ }^{1,2}$, Brian Malig ${ }^{1}$, Rachel Broadwin ${ }^{1}$, Keita Ebisu', Rupa Basu', Ellen B. Gold ${ }^{3}$, Lihong Qi ${ }^{3}$, Carol A. Derby ${ }^{4}$, Sung Kyun Park ${ }^{5}$ and Xiangmei (May) $\mathrm{Wu}^{1^{*}}$ (i)

\begin{abstract}
Background: Exposure to particulate matter air pollution has been associated with cardiovascular disease (CVD) morbidity and mortality; however, most studies have focused on fine particulate matter $\left(\mathrm{PM}_{2.5}\right)$ exposure and CVD. Coarse particulate matter $\left(\mathrm{PM}_{10-2.5}\right)$ exposure has not been extensively studied, particularly for long-term exposure, and the biological mechanisms remain uncertain.
\end{abstract}

Methods: We examined the association between ambient concentrations of $\mathrm{PM}_{10-2.5}$ and inflammatory and hemostatic makers that have been linked to CVD. Annual questionnaire and clinical data were obtained from 1694 women ( $\geq 55$ years old in 1999) enrolled in the longitudinal Study of Women's Health Across the Nation (SWAN) at six study sites from 1999 to 2004. Residential locations and the USEPA air monitoring network measurements were used to assign exposure to one-year $\mathrm{PM}_{10-2.5}$, as well as co-pollutants. Linear mixed-effects regression models were used to describe the association between $\mathrm{PM}_{10-2.5}$ exposure and markers, including demographic, health and other covariates.

Results: Each interquartile $\left(4 \mathrm{\mu g} / \mathrm{m}^{3}\right)$ increase in one-year $\mathrm{PM}_{10-2.5}$ exposure was associated with a 5.5\% (95\% confidence interval [CI]: 1.8, 9.4\%) increase in levels of plasminogen activator inhibitor-1 (PAl-1) and 4.1\% (95\% Cl: $0.1,8.6 \%$ increase in high-sensitivity C-creative Protein (hs-CRP). Stratified analyses suggested that the association with PAl-1 was particularly strong in some subgroups, including women who were peri-menopausal, were less educated, had a body mass index lower than 25, and reported low alcohol consumption. The association between PM $10-2.5$ and PAl-1 remained unchanged with adjustment for PM 2.5 , ozone, nitrogen dioxide, and carbon monoxide. Conclusions: Long-term $\mathrm{PM}_{10-2.5}$ exposure may be associated with changes in coagulation independently from $\mathrm{PM}_{2.5}$, and thus, contribute to CVD risk in midlife women.

Keywords: Coarse particulate matter, Long-term exposure, Inflammation, Coagulation, Women, Menopause

\footnotetext{
* Correspondence: xiangmei.wu@oehha.ca.gov

${ }^{1}$ Air and Climate Epidemiology Section, Office of Environmental Health

Hazard Assessment, California Environmental Protection Agency, 1515 Clay

Street, 16th Floor, Oakland, CA 94612, USA

Full list of author information is available at the end of the article
}

(c) The Author(s). 2020 Open Access This article is licensed under a Creative Commons Attribution 4.0 International License, which permits use, sharing, adaptation, distribution and reproduction in any medium or format, as long as you give appropriate credit to the original author(s) and the source, provide a link to the Creative Commons licence, and indicate if changes were made. The images or other third party material in this article are included in the article's Creative Commons licence, unless indicated otherwise in a credit line to the material. If material is not included in the article's Creative Commons licence and your intended use is not permitted by statutory regulation or exceeds the permitted use, you will need to obtain permission directly from the copyright holder. To view a copy of this licence, visit http://creativecommons.org/licenses/by/4.0/. The Creative Commons Public Domain Dedication waiver (http://creativecommons.org/publicdomain/zero/1.0/) applies to the data made available in this article, unless otherwise stated in a credit line to the data. 


\section{Background}

Cardiovascular disease (CVD) is the leading cause of death for men and women in the US [1]. Risk factors such as sex, age, increased blood pressure, high cholesterol, and smoking, only account for approximately $50 \%$ of cardiac events [2]. Evidence suggests that exposure to particulate matter air pollution is associated with cardiovascular morbidity and mortality, potentially through its ability to increase inflammation and coagulation [3].

Given the known adverse health effects, the United States Environmental Protection Agency (USEPA) regulates particulate matter by setting regulatory standards and enforcing mandatory monitoring for particulate matter with an aerodynamic diameter smaller than 2.5 and $10 \mu \mathrm{m}\left(\mathrm{PM}_{2.5}\right.$ and $\mathrm{PM}_{10}$, respectively) [4]. Most available research has been focused on the health impacts of $\mathrm{PM}_{2.5}$ exposure; however, potential health effects from exposure to coarse particulate matter with an aerodynamic diameter between 2.5 and $10 \mu \mathrm{m}\left(\mathrm{PM}_{10-2.5}\right.$ or coarse particles) might differ from exposure to $\mathrm{PM}_{2.5}$ due to the components, sources, and size. Coarse particles are primarily generated by mechanical grinding and resuspension of solid material and may have a high biological content (such as pollen, fungi, and endotoxins) or crustal matter (such as aluminum and silicon and heavy metals) [5]. As a result of size difference, $\mathrm{PM}_{2.5}$ deposits deeper in the alveolar region of the lungs, while $\mathrm{PM}_{10-2.5}$ mainly deposits higher in the airways [4]. Our understanding of the health impacts from $\mathrm{PM}_{10-2.5}$ exposure is limited, and thus, no specific regulatory standards exist for $\mathrm{PM}_{10-2.5}$ [4].

Evidence also suggests that $\mathrm{PM}_{10-2.5}$ is associated with respiratory and cardiovascular morbidity and mortality [6-11], but the majority of the previous studies have focused on short-term exposure. Powell et al. reported a significant positive association between hospitalizations for CVD and same-day $\mathrm{PM}_{10-2.5}$ levels in a Medicare population, aged $\geq 65$ years, in the US [9]. In a systematic review and meta-analysis, respiratory mortality and hospitalizations were increased by $1.4 \%$ ( $95 \%$ confidence interval (CI): $0.5-2.4 \%)$ and $1.0 \%$ (95\% CI: $0.1-1.8 \%)$, respectively, per $10 \mu \mathrm{g} / \mathrm{m}^{3}$ increase in short-term $\mathrm{PM}_{10-2.5}$ exposure [12]. However, the associations between longterm $\mathrm{PM}_{10-2.5}$ exposure and mortality/morbidity, which may be derived from different mechanisms from shortterm exposure, have been unclear. Early studies reviewed by Brunekreef and Forsberg did not present associations between mortality and morbidity with long-term exposures to $\mathrm{PM}_{10-2.5}$ [13]. The meta-analysis study Adar et al. reported a summary estimate of a $2.1 \%$ (95\% CI: 1.6 to $5.8 \%$ ) higher mortality rate per $10 \mu \mathrm{g} / \mathrm{m}^{3}$ increment in long-term $\mathrm{PM}_{10-2.5}$ concentration based on six cohort studies, but this association diminished after adjustment for $\mathrm{PM}_{2.5}$ [12]. Recent studies examining specific health endpoints have linked long-term exposure to coarse PM with right ventricular dysfunction and hypertension [14, 15].

Furthermore, few studies have assessed associations between $\mathrm{PM}_{10-2.5}$ and markers of inflammation and coagulation that are predictive of CVD. Investigating the association between particulate matter and CVD biomarkers could help postulate the underlying physiological mechanisms. Adar et al. found that the endotoxin component of the 5-year concentrations of $\mathrm{PM}_{10-2.5}$ was associated with increased inflammation scores, while the copper component of $\mathrm{PM}_{10-2.5}$ was associated with an elevated coagulation score [16].

The Study of Women's Health Across the Nation (SWAN) cohort was designed to follow a multi-racial/ethnic cohort of midlife women through menopausal transition [17]. With longitudinal biomonitoring across years, this study offers a unique opportunity to study CVD risks associated with long-term $\mathrm{PM}_{10-2.5}$ exposure. With previous work having shown associations between CVD markers and exposures to ambient $\mathrm{PM}_{2.5}$ and gaseous pollutants $[18,19]$, further research with respect to $\mathrm{PM}_{10-2.5}$ exposure and CVD markers in the SWAN cohort would advance the understanding of whether $\mathrm{PM}_{10-2.5}$ are associated with inflammation and coagulation. Moreover, with the ability to assess other air pollutants, this study could further evaluate confounding by co-pollutants and improve the understanding of the potential independent impact of $\mathrm{PM}_{10-2.5}$ exposure on CVD.

\section{Methods}

\section{Study population}

The SWAN study design and recruitment has been previously described [17]. The present study includes data from six sites: Chicago, Illinois; Detroit, Michigan; Los Angeles, California; Newark, New Jersey; Oakland, California; and Pittsburgh, Pennsylvania. Recruitment included non-Hispanic White women at all sites as well as women from one other racial/ethnic group at each site: African American in Chicago, Pittsburgh, and Detroit; Asian in Oakland (Chinese) and Los Angeles (Japanese); and Hispanic (including women of Central American, Mexican, and Caribbean origin) in Newark. The inclusion criteria for the study at baseline were: being 42 to 52 years of age, having an intact uterus and at least one ovary, no current use of exogenous hormones, not being pregnant or lactating, and having had at least one menstrual period in the last 3 months. Approximately 450 eligible women at each study site have been followed up with annual clinical assessments and interviews.

The present study includes serum samples collected at clinical visits 3 (1999-2000) through visits 7 (20032004), since $\mathrm{PM}_{2.5}$, a key component for calculating $\mathrm{PM}_{10-2.5}$ concentration, was not routinely measured nationwide until 1998. 


\section{CVD marker measurement and analysis}

Fasting blood was drawn at each annual SWAN clinical visit and assayed as described previously [18, 20]. The inflammatory and hemostatic markers assessed in this study included high sensitivity C-reactive protein (hsCRP), fibrinogen, factor VII coagulant (factor VIIc), tissue-type plasminogen activator antigen (tPA-ag), and plasminogen activator inhibitor Type 1 (PAI-1). They serve as markers of the following processes, including systemic inflammation (hs-CRP), formation of blood clots when endothelial damage occurs (fibrinogen and factor VIIc), and fibrinolysis (tPA-ag and PAI-1) [21].

Hs-CRP was measured in serum by immunonephelometry using Behring reagents. Fibrinogen and Factor VII-C were measured in frozen citrated plasma by an assay in which clotting time is measured and compared to a control on a MLA $1400 \mathrm{C}$ coagulation analyzer. PAI-1 and tPA-ag, both free form and tPA-PAI-1 complexes, were measured in plasma using enzyme-linked immunosorbent assay (ELISA) technique (American Diagnostica). A human single chain tPA-ag was used as a standard calibrated against an international standard (National Institute for Biological Standards and Control, Hertfordshire, United Kingdom). PAI-1 was detected using a solid phased monoclonal antibody and a second enzyme-labeled goat antiserum (American Diagnostica) [22]. PAI-1, tPA-ag and hs-CRP were measured at every visit, while fibrinogen and factor VIIc were measured only for visits 3, 5 and 7. All bioassay analyses were conducted in the Medical Research Laboratory, Lexington Kentucky.

Additionally, hs-CRP values $>10 \mathrm{mg} / \mathrm{L}$ were excluded from the analyses because they may be indicative of severe infection, major trauma, or chronic inflammatory disease $(0.1 \%$ of all observations). For the other inflammatory and hemostatic markers, extreme values (outside the mean \pm 3 standard deviations after log transformation) were excluded from study $(<3 \%)$ as they may indicate laboratory error.

\section{Exposure assignment}

A residential history was obtained for each SWAN participant. Each residence was geocoded, with its coordinate randomly moved up to $400 \mathrm{ft}$ (approximately one block) away to maintain confidentiality. A $20 \mathrm{~km}$ circular buffer was created around each address using ArcGIS v10.0 (Environmental Systems Research Institute 2016). The exposure measured by the monitor located in the buffer will be assigned to the participant. For instances in which multiple monitors were located within the buffer, one was chosen based on 1) distance from the residence, and 2) number of visits with exposure data available, which could differ by monitor because of differences in operating dates. Priority was given to the closer monitor to reduce exposure misclassification, but the more distant monitor was chosen if the ratio of (available visits of the distant monitor / available visits of the closer monitor) was greater than the ratio of (the distance to the distant monitor / distance to the closer monitor). If a participant moved between visits, exposure was weighted based on time at each residence using the available move date. If no move date was available, exposure was estimated using the midpoint between the two visits.

Daily $\mathrm{PM}_{10-2.5}$ was calculated as the difference of daily $\mathrm{PM}_{2.5}$ and $\mathrm{PM}_{10}$ concentrations measured at the same monitoring site on the same day, whenever available. Ambient $\mathrm{PM}_{2.5}$ and $\mathrm{PM}_{10}$ concentrations were obtained from the USEPA air monitoring network, which were monitored every third or sixth day, or daily. The data for these measures were in a 24-h average concentration format. There were fewer monitors for $\mathrm{PM}_{10}$, and some monitors take measurements less frequently, which limited the number of measurements of $\mathrm{PM}_{10}$, and thus resulting in fewer calculated $\mathrm{PM}_{10-2.5}$ measurements. Furthermore, given the uncertainty of extreme values, the top and bottom $2.5 \%$ of $\mathrm{PM}_{10}$ and of $\mathrm{PM}_{2.5}$ data were trimmed.

To assess the potential confounding effects of ambient gases, ozone $\left(\mathrm{O}_{3}\right)$, carbon monoxide $(\mathrm{CO})$, nitrogen dioxide $\left(\mathrm{NO}_{2}\right)$, and sulfur dioxide $\left(\mathrm{SO}_{2}\right)$ concentrations were also obtained. The available data were daily 8 -h maximum concentrations for ozone and $\mathrm{CO}$, and one-hour maximum concentrations for $\mathrm{NO}_{2}$ and $\mathrm{SO}_{2}$. It should be noted that some monitors, specifically in Michigan, only monitored $\mathrm{O}_{3}$ during the summer time. All air pollutant data were downloaded from the USEPA Air Data website (https://aqs.epa.gov/aqsweb/documents/data_mart_welcome.html, accessed September 2010).

In this study, we focused on the impact of long-term $\mathrm{PM}_{10-2.5}$ exposure, namely the average prior one-year exposure. The six-month exposure was also calculated and considered as intermediate-exposure for a sensitivity analysis. Daily readings were used to calculate average exposure levels for six-month and one-year prior to each blood draw. To simplify, months were considered to be 30-day increments. A minimum of 9 days was necessary for calculating a one-month average; at least 5 months was necessary for a six-month average; and at least 10 months for a one-year average.

\section{Covariates}

The baseline questionnaire, completed when participants were recruited, collected non-time varying covariates on socioeconomic status, for example, residence address, date of birth (for calculating age), race/ethnicity (categorized into White, African American, Asian, or Hispanic), and education (high school or less, some college, or college graduate). 
At annual clinic visits, SWAN participants completed questionnaires providing visit-specific information related to medical history, psychosocial environment, lifestyle behaviors, menstrual bleeding patterns, illness, and use of medications since their last visit. Menopausal status was determined based on self-reported bleeding patterns according to standard definitions, and categorized into pre-, early peri-, late peri-, post-menopause, and unknown [23]. Height and weight were measured to calculate body mass index (BMI). Alcohol consumption was divided into three categories developed by Laura L Schott (EDC Coordinating Center): low $=$ none or $<1$ serving $/$ month, moderate $=$ up to $1 /$ week or $0.3 /$ day, and high $=2+/$ week or $>0.3 /$ day .

\section{Statistical analysis}

For each air pollutant and CVD marker, summary statistics were calculated. Biomarker levels were log-transformed to meet the normality assumption. Correlations of markers and air pollutants were calculated based on visit 3 data, as it had the largest sample size among the included visits and serum samples and serves as the baseline for our study.

To study the association between $\mathrm{PM}_{10-2.5}$ and CVD biomarkers, we used linear mixed-effects regression models with each biomarker as a continuous, dependent variable. The average prior one-year $\mathrm{PM}_{10-2.5}$ exposure was included in a single-pollutant model along with covariates. A random intercept was used to account for covariance of measurements, as multiple longitudinal measurements collected from the same woman are highly correlated. Site was included as a fixed effect because participants were nested within each site. Firstorder ante-dependence structure was specified for repeated measurements from each participant [19].

Potential covariates were evaluated based on statistical significance and Akaike Information Criterion (AIC) value to control for confounding and goodness of model fit, respectively, without adding over fitted covariates. With all potential covariates, a backward elimination of variables, one at a time, was performed. Variables that have been tested but not included in the final model were: season (cold/warm), physical activity score (continuous), depress symptom score (continuous), poverty score of the ZCTA the participant resided (continuous), antilipidemic medication use (yes/no), and depression medication (yes/no). These variables that were not statistically associated with outcome markers and whose elimination did not change AIC were excluded from the model. The final model included study site, race/ethnicity, education, and visit-specific variables including age (continuous), BMI (continuous), menopausal status, active smoking (yes/no), and alcohol consumption.

Visits after major CVD events, including myocardial infarction, coronary heart failure, stroke, percutaneous coronary intervention, and coronary artery bypass graft, were censored from analyses. We also censored visits for which women did not fast $12 \mathrm{~h}$ before blood draw. New Jersey data from visits six and seven were censored because only a few participants had serum sample data for those visits.

Potential effect modification was considered by targeting subgroups for stratification. These groups included BMI (below vs. equal to or above $25 \mathrm{~kg} / \mathrm{m}^{2}$ ), current menopause transition stage (early or late perimenopausal vs. post-menopausal; pre-menopausal was not considered due to small sample size), alcohol consumption category (low vs. medium or high), and education (high school or less vs. some college or more). Each stratified variable was omitted from the base model.

To evaluate the confounding by co-pollutants, we used two-pollutant models, incorporating each of $\mathrm{PM}_{2.5}$, ozone, $\mathrm{CO}, \mathrm{NO}_{2}$, and $\mathrm{SO}_{2}$, respectively, along with one-year $\mathrm{PM}_{10-2.5}$ in the final models mentioned above, to evaluate the potential confounding effects of each co-pollutant.

Several sensitivity analyses were run excluding women who: had diabetes, were currently smoking, only had one or two visits, with pre-existing medical conditions (including major CVD events defined above, angina, hypertension, or diabetes) and/or medication use, and had unknown menopausal status and/or hormone use.

Analyses were performed in SAS 9.4 (SAS Institute, Cary, NC). All tests were two-sided and $p$-values $<0.05$ were considered statistically significant. All results were expressed as the percent change in markers per respective interquartile range increase in air pollutant based on averaging times using the formula $\left[100 \times\left(\exp ^{(\beta}\right.\right.$ per unit pollutant $* \mathrm{IQR})-1)]$.

\section{Results}

After applying the exclusions described above, 1694 women with 5982 observations during the study period were available for analyses. Approximately $68 \%$ of the women had three or more clinic visits between 1999 and 2004. The race/ethnicity distribution by study site for this population reflected the SWAN sampling strategy discussed previously. Over $50 \%$ of women in Chicago, Los Angeles, and Oakland had completed college, while in Detroit, Newark, and Pittsburgh, approximately 27\% of the women had completed college. Most women in the study were overweight $(25<\mathrm{BMI} \leq 30)$ or obese $(B M I \geq 30)$, with the exception of women from the Oakland and Los Angeles sites. Additionally, most women in this study were neither current smokers nor high alcohol consumers $\quad(2+$ servings/week or $>0.3$ servings/day $)$ (Table 1).

The distributions of CVD biomarkers by risk factor status reflect the potential risk factors associated with inflammation and coagulation (Table 2). Women who 
Table 1 Characteristics of the Study Population, SWAN Cohort, 1999-2004

\begin{tabular}{|c|c|c|c|c|c|c|}
\hline & $\begin{array}{l}\text { Detroit, MI } \\
n=208\end{array}$ & $\begin{array}{l}\text { Chicago, IL } \\
n=372\end{array}$ & $\begin{array}{l}\text { Oakland, CA } \\
n=343\end{array}$ & $\begin{array}{l}\text { Los Angeles, CA } \\
n=144\end{array}$ & $\begin{array}{l}\text { Newark, NJ } \\
n=250\end{array}$ & $\begin{array}{l}\text { Pittsburgh, PA } \\
n=377\end{array}$ \\
\hline \multicolumn{7}{|l|}{ Race/Ethnicity (\%) } \\
\hline African American & 81 & 52 & - & - & - & 34 \\
\hline Chinese & - & - & 58 & - & - & - \\
\hline Hispanic & - & - & - & - & 70 & - \\
\hline Japanese & - & - & - & 81 & - & - \\
\hline White & 19 & 48 & 42 & 19 & 30 & 66 \\
\hline \multicolumn{7}{|l|}{ Education (\%) } \\
\hline$\leq$ High school & 36 & 12 & 19 & 20 & 54 & 23 \\
\hline Some college & 42 & 30 & 23 & 29 & 22 & 34 \\
\hline$\geq$ College & 17 & 58 & 58 & 51 & 20 & 43 \\
\hline Total number of visits & 804 & 1420 & 1454 & 299 & 486 & 1519 \\
\hline \multicolumn{7}{|l|}{ Menopausal status (\%) } \\
\hline Pre & 4 & 5 & 7 & 5 & 4 & 7 \\
\hline Early peri & 35 & 41 & 37 & 41 & 51 & 34 \\
\hline Late peri & 12 & 10 & 10 & 9 & 11 & 11 \\
\hline Post & 36 & 37 & 34 & 35 & 26 & 32 \\
\hline Unknown & 12 & 7 & 13 & 10 & 9 & 15 \\
\hline \multicolumn{7}{|l|}{ Body Mass Index (\%) } \\
\hline$<25$, normal & 12 & 20 & 58 & 63 & 22 & 28 \\
\hline 25-30, overweight & 23 & 32 & 22 & 23 & 32 & 32 \\
\hline$>30$, obese & 63 & 40 & 18 & 14 & 39 & 40 \\
\hline \multicolumn{7}{|l|}{ Alcohol consumption (\%) } \\
\hline Low & 65 & 37 & 60 & 49 & 59 & 49 \\
\hline Medium & 17 & 27 & 20 & 22 & 24 & 31 \\
\hline High & 14 & 23 & 18 & 28 & 12 & 19 \\
\hline Current smoker (\%) & 29 & 15 & 3 & 9 & 16 & 14 \\
\hline Diagnosed diabetes (\%) & 20 & 8 & 5 & 5 & 10 & 7 \\
\hline Any CVD event (\%) & 3.8 & 0.4 & 1.2 & 0 & 0.4 & 1.8 \\
\hline
\end{tabular}

Note: percentages do not always add up to $100 \%$ because of missing data

were current smokers, had diagnosed diabetes, or were obese had higher levels of the inflammatory and hemostatic markers. African American and Hispanic women tended to have higher levels of the inflammatory/ hemostatic markers while Asian women had lower. The two inflammatory markers, hs-CRP and fibrinogen, were moderately correlated (Pearson correlation coefficient $(r)=0.39)$, as were the two hemostatic markers, PAI-1 and tPA-ag $(r=0.50)$.

The average prior one-year $\mathrm{PM}_{10-2.5}$ exposures for all the SWAN sites were $10.9 \pm 3.6 \mu \mathrm{g} / \mathrm{m}^{3}$ (Table 3). The average prior six-month exposure was similar $(10.8 \pm$ $\left.4.0 \mu \mathrm{g} / \mathrm{m}^{3}\right)$, and had a slightly larger sample size $(N=$ $5466)$ than the one-year exposure $(N=5175)$, because $\mathrm{PM}_{2.5}$ measurements started from 1998 which limited the ability to calculate prior one-year exposure for some early visits. Los Angeles site had the highest levels of one-year $\mathrm{PM}_{10-2.5}$ exposure at $17.5 \pm 2.3 \mu \mathrm{g} / \mathrm{m}^{3}$, while Pittsburgh had the lowest levels at $8.5 \pm 3.8 \mu \mathrm{g} / \mathrm{m}^{3}$. Due to the limited availability of $\mathrm{PM}_{10}$ monitors, however, Los Angeles only had a small number of visits with colocated $\mathrm{PM}_{10}$ and $\mathrm{PM}_{2.5}$ monitors, and thus matched $\mathrm{PM}_{10-2.5}$ data. Distributions of one-year average exposure of co-pollutants, including $\mathrm{PM}_{2.5}$, ozone, $\mathrm{CO}, \mathrm{NO}_{2}$ and $\mathrm{SO}_{2}$ exposure, can be found in Table S1.

We observed that an interquartile $\left(4 \mu \mathrm{g} / \mathrm{m}^{3}\right)$ increase in the prior one-year exposure of $\mathrm{PM}_{10-2.5}$ was associated with a $5.5 \%(1.8,9.4 \%)$ increase in PAI-1 level. This association was consistent for the six-month exposure window, with a $4.0 \%(0.3,7.8 \%)$ increase in PAI-1 per $4 \mu \mathrm{g} / \mathrm{m}^{3}$ increase in $\mathrm{PM}_{10-2.5}$. The inflammation marker, hs-CRP, was also associated with $\mathrm{PM}_{10-2.5}$, with a $4.1 \%$ 
Table 2 Distribution of inflammatory and hemostatic biomarkers by demographic factors for SWAN cohort, 1999-2004

\begin{tabular}{|c|c|c|c|c|c|c|c|}
\hline Variable & & $N^{b}$ & hs-CRP ${ }^{d}$ & Fibrinogen & Factor VIlc & tPA-ag & PAI-1 \\
\hline (Unit) & & & $\mathrm{mg} / \mathrm{l}$ & $\mathrm{mg} / \mathrm{dl}$ & $\%$ & $\mathrm{ng} / \mathrm{ml}$ & $\mathrm{ng} / \mathrm{ml}$ \\
\hline$N$ of samples ${ }^{c}$ & & 5982 & 4913 & 2638 & 2604 & 5634 & 5587 \\
\hline All participants & & 1694 & $1.6(3.4)$ & $367.8(81.0)$ & $130.9(34.1)$ & $7.1(4.4)$ & $14.6(19.5)$ \\
\hline \multirow[t]{5}{*}{ Race/Ethnicity } & African American & $32 \%$ & $2.7(4.4)$ & $388.0(86.4)$ & $130.0(34.2)$ & $7.9(4.7)$ & $16.6(20.2)$ \\
\hline & Asian & $18 \%$ & $0.8(1.3)$ & $354.9(72.2)$ & $129.0(28.6)$ & $6.2(3.9)$ & $11.2(16.0)$ \\
\hline & Hispanic & $6 \%$ & $2.6(4.0)$ & $370.0(79.8)$ & $129.1(34.2)$ & $8.7(4.3)$ & $20.1(22.0)$ \\
\hline & White & $44 \%$ & $1.6(3.1)$ & $362.8(76.8)$ & $134.6(34.9)$ & $6.9(4.1)$ & $14.0(19.7)$ \\
\hline & $p$-value $e^{f}$ & & $<0.01$ & $<0.01$ & $<0.01$ & $<0.01$ & $<0.01$ \\
\hline \multirow[t]{4}{*}{ Education } & $\leq$ High school & $23 \%$ & $1.7(3.6)$ & $373.6(93.1)$ & $134.1(34.0)$ & $7.4(4.7)$ & $15.8(20.3)$ \\
\hline & Some college & $30 \%$ & $2.1(3.7)$ & $373.4(74.3)$ & $132.7(33.2)$ & $7.4(4.4)$ & $16.0(21.4)$ \\
\hline & $\geq$ College & $45 \%$ & $1.4(3.0)$ & $362.8(81.6)$ & $130.0(33.2)$ & $6.7(4.3)$ & $12.9(17.8)$ \\
\hline & $p$-value & & 0.03 & 0.44 & 0.04 & 0.11 & 0.13 \\
\hline \multirow[t]{6}{*}{ Menopausal status } & Pre & 345 & $1.6(2.9)$ & $352.2(73.2)$ & $129.1(33.2)$ & $7.1(4.0)$ & $15.2(21.2)$ \\
\hline & Early peri & 2297 & $1.5(3.0)$ & $362.4(81.0)$ & $127.2(29.7)$ & $7.0(4.0)$ & $14.5(18.8)$ \\
\hline & Late peri & 624 & $1.6(3.5)$ & $376.5(85.0)$ & $134.1(32.7)$ & $7.7(4.7)$ & $17.0(23.2)$ \\
\hline & Post & 2017 & $1.8(3.7)$ & $380.9(82.5)$ & $136.4(34.8)$ & $7.4(4.9)$ & $14.8(19.4)$ \\
\hline & Unknown & 687 & $2.0(4.0)$ & $362.6(75.8)$ & $136.0(37.6)$ & $6.6(4.1)$ & $12.2(17.0)$ \\
\hline & $p$-value & & $<0.01$ & 0.28 & $<0.01$ & $<0.01$ & $<0.01$ \\
\hline \multirow[t]{4}{*}{ Body Mass Index $\left(\mathrm{kg} / \mathrm{m}^{2}\right)$} & $<25$ & 1947 & $0.8(1.3)$ & $344.8(64.1)$ & $123.5(28.9)$ & $5.4(3.2)$ & $8.4(10.2)$ \\
\hline & $25-30$ & 1672 & $1.7(2.6)$ & $365.7(72.9)$ & $133.7(34.9)$ & $7.1(3.6)$ & $14.8(17.5)$ \\
\hline & $>30$ & 2178 & $3.9(4.4)$ & $395.3(82.8)$ & $137.3(35.7)$ & $8.8(4.1)$ & $22.6(23.5)$ \\
\hline & $p$-value & & $<0.01$ & $<0.01$ & $<0.01$ & $<0.01$ & $<0.01$ \\
\hline \multirow[t]{3}{*}{ Current smoker } & Yes & 805 & $2.4(4.1)$ & $390.9(87.9)$ & $128.1(32.4)$ & $7.9(4.4)$ & $18.7(23.6)$ \\
\hline & No & 4959 & $1.6(3.1)$ & $364.6(78.5)$ & $128.1(32.4)$ & $7.0(4.3)$ & $13.8(18.5)$ \\
\hline & $p$-value & & 0.02 & $<0.01$ & 0.14 & $<0.01$ & 0.04 \\
\hline \multirow[t]{4}{*}{ Alcohol consumption ${ }^{\mathrm{e}}$} & Low & 3084 & $1.7(3.7)$ & $375.8(83.2)$ & $132.7(33.1)$ & $7.3(4.6)$ & $15.4(21.3)$ \\
\hline & Moderate & 1463 & $1.7(3.4)$ & $367.2(79.3)$ & $130.0(32.3)$ & $7.0(4.2)$ & $14.2(18.1)$ \\
\hline & High & 1133 & $1.4(2.5)$ & $348.9(75.0)$ & $130.4(36.0)$ & $6.7(4.3)$ & $12.2(17.2)$ \\
\hline & $p$-value & & 0.31 & $<0.01$ & 0.18 & 0.38 & 0.11 \\
\hline \multirow[t]{3}{*}{ Diagnosed diabetes } & Yes & 530 & $4.4(4.8)$ & $401.1(88.9)$ & $141.9(36.3)$ & $9.1(4.4)$ & $24.4(27.8)$ \\
\hline & No & 5449 & $1.5(3.1)$ & $365.4(80.3)$ & $130.9(32.3)$ & $7.0(4.3)$ & $13.8(18.2)$ \\
\hline & $p$-value & & $<0.01$ & 0.30 & $<0.01$ & $<0.01$ & $<0.01$ \\
\hline \multirow[t]{3}{*}{ Any CVD event } & Yes & 84 & $3.4(4.3)$ & $418.9(99.1)$ & $145.5(29.9)$ & $7.1(4.4)$ & $19.6(23.7)$ \\
\hline & No & 5898 & $1.6(3.4)$ & $367.1(80.8)$ & $130.9(34.1)$ & $8.5(5.0)$ & $14.5(19.5)$ \\
\hline & $p$-value & & 0.03 & 0.08 & 0.52 & 0.41 & 0.25 \\
\hline
\end{tabular}

${ }^{\mathrm{a}}$ Data shown in each grid is the median followed by (interquartile range), excluding $\mathrm{N}$

${ }^{\mathrm{b}}$ For ethnicity/education, the \% show in this column are the percentage of participants in each category among all participants. Percentages do not always add up to $100 \%$ because of missing data. For the visit-specific variables, $\mathrm{N}$ is the number of observations, not women; each participant could have data from multiple visits and could be in different categories at different visits

'Sample size varied by biomarkers. Visits without any blood data or any matched exposure data were excluded. Visits 6 and 7 in New Jersey site were censored due to small sample size. Visits that happened after any CVD events were excluded. Marker values out of reasonable ranges were excluded

${ }^{d}$ For hs-CRP, values $>10 \mathrm{mg} / \mathrm{l}$ were not included due to the concern of possible severe inflammation

${ }^{\mathrm{e}}$ Alcohol category consists of three categories developed by Laura L Schott (EDC Coordinating Center): low $=$ none or $<1$ serving $/$ month, moderate $=$ up to $1 /$ week or $0.3 /$ day, high $=2+/$ week or $>0.3 /$ day

f $p$-value are from the Type 3 test of fixed effects using mixed effect model, with all variables included as fixed effects and a random intercept account for covariance of measurements. Site was also included as a fixed effect and participants were nested within each site, as multiple longitudinal measurements collected from the same woman are highly correlated. First-order ante-dependence structure was specified for repeated measurements from each participant 
Table 3 Descriptive statistics for prior one-year exposure to coarse particulate matter $\left(\mathrm{PM}_{10-2.5}\right)$ concentrations $\left(\mu \mathrm{g} / \mathrm{m}^{3}\right)$ for SWAN sites, 1999-2004

\begin{tabular}{lrrrrr}
\hline Site & N & Mean & SD & Median & IQR \\
\hline All sites & 5175 & 10.9 & 3.6 & 11.5 & 4.0 \\
By site & & & & & \\
$\quad$ Detroit, MI & 719 & 10.6 & 3.5 & 10.3 & 3.9 \\
$\quad$ Chicago, IL & 1296 & 12.1 & 1.9 & 12.0 & 2.4 \\
$\quad$ Oakland, CA & 1229 & 10.9 & 1.8 & 11.6 & 2.2 \\
Los Angeles, CA & 209 & 17.5 & 2.3 & 18.4 & 1.6 \\
$\quad$ Newark, NJ & 366 & 12.4 & 4.9 & 12.8 & 5.7 \\
$\quad$ Pittsburgh, PA & 1356 & 8.5 & 3.8 & 7.4 & 6.8 \\
\hline
\end{tabular}

$(-0.1,8.6 \%)$ and a $6.0 \%(1.7,10.5 \%)$ increase in hs-CRP per $4 \mu \mathrm{g} / \mathrm{m}^{3}$ increase in prior one-year and six-month $\mathrm{PM}_{10-2.5}$ exposure, respectively. Associations with other markers were not observed.

Sensitivity analyses were conducted with some subgroups removed. Positive associations between $\mathrm{PM}_{10-2.5}$ and PAI-1 levels remained statistically significant in models that excluded women with diagnosed diabetes, those who reported current smoking, who did not complete at least three clinic visits, who reported medical preconditions, who reported medication use, and who had unknown menopausal status and hormone use, respectively (Table $\mathrm{S} 2$ ). The marginal association between $\mathrm{PM}_{10-2.5}$ and hs-CRP became statistically significant in the model restricting analysis to women who completed three or more visits and in the model excluding smokers; however, the association disappeared in other sensitivity analyses.

Potential effect modifiers were evaluated for the oneyear $\mathrm{PM}_{10-2.5}$ exposure, and some subgroups appeared to have experienced elevated risks (Table 4). For a $4 \mu \mathrm{g} /$ $\mathrm{m}^{3}$ increase in one-year $\mathrm{PM}_{10-2.5}$, PAI-1 increased by
9.2\% (1.4, 17.7\%) in women with a BMI $<25,7.5 \%$ (2.2, $13.2 \%)$ in peri-menopausal women, $7.6 \%(0.6,15.1 \%)$ in women with equivalent or less than a high school education, and $7.5 \%(2.3,13.0 \%)$ in women who reported low alcohol consumption. Additionally, women who reported low alcohol consumption had an $8.8 \%$ (2.7, $15.3 \%)$ increase in hs-CRP, and women with equivalent or less than a high school education had 2.4\% (0.1, 4.7\%) decrease in factor VIIc, per $4 \mu \mathrm{g} / \mathrm{m}^{3}$ increase in $\mathrm{PM}_{10-2.5}$. The stratification results for the other inflammatory and hemostatic markers were not statistically significant.

The co-pollutant models were conducted in subsets of observations compared with the single pollutant models of $\mathrm{PM}_{10-2.5}$, given the availability of co-pollutant data. For most sites, 70-98\% of serum samples had matched copollutant exposure, except for ozone in Detroit $(0.5 \%)$ (not included in the analysis) and Newark (48\%), $\mathrm{NO}_{2}$ in Detroit (57\%), Chicago (65\%), and Newark (65\%), and $\mathrm{SO}_{2}$ in Oakland (53\%) (Table S1). One-year $\mathrm{PM}_{10-2.5}$ exposure appeared to be moderately correlated with one-year $\mathrm{PM}_{2.5}$ $(r=0.29)$ and $\mathrm{NO}_{2}(r=0.30)$. The interquartile ranges for the prior one-year average exposures of co-pollutants was $3 \mu \mathrm{g} / \mathrm{m}^{3}$ for $\mathrm{PM}_{2.5}, 0.007 \mathrm{ppm}$ for ozone, $0.3 \mathrm{ppm}$ for $\mathrm{CO}$, $5 \mathrm{ppb}$ for $\mathrm{NO}_{2}$, and $3.0 \mathrm{ppb}$ for $\mathrm{SO}_{2}$.

Our previous studies have found that one-year exposures to $\mathrm{PM}_{2.5}, \mathrm{NO}_{2}$, and $\mathrm{CO}$ were positively associated with PAI-1 $[18,19]$. In two-pollutant models along with $\mathrm{PM}_{10-2.5}, \mathrm{PM}_{2.5}, \mathrm{CO}$, and $\mathrm{NO}_{2}$ were each still positively associated with PAI-1 levels, and the associations were stronger for $\mathrm{PM}_{2.5}, \mathrm{CO}$, and $\mathrm{NO}_{2}$ than $\mathrm{PM}_{10-2.5}$. In contrast, $\mathrm{O}_{3}$ had a negative association with PAI-1. Nevertheless, these co-pollutants did not confound the association between $\mathrm{PM}_{10-2.5}$ and PAI-1 (Fig. 1 and Table S3). Specifically, the positive association remained for PAI-1 and $\mathrm{PM}_{10-2.5}$ from the single pollutant model when considering co-exposure to $\mathrm{PM}_{2.5}$, with a $4.8 \%$ (1.0, 8.7\%) increase per $4 \mu \mathrm{g} / \mathrm{m}^{3}$ increase in $\mathrm{PM}_{10-2.5}$.

Table 4 Adjusted associations between PM $_{10-2.5}$ and cardiovascular disease markers for SWAN cohort, 1999-2004 ${ }^{\mathrm{a}}$

\begin{tabular}{lccccc}
\hline Marker & hs-CRP & Fibrinogen & Factor VIlc & tPA-ag & PAI-1 \\
\hline Total & $4.1(-0.1,8.6)^{*}$ & $-0.1(-1.0,0.8)$ & $-0.1(-1.2,1.1)$ & $0.4(-1.4,2.3)$ & $5.5(1.8,9.4)^{* * *}$ \\
BMI $<25$ & $5.4(-3.1,14.5)$ & Did not converge & $0.6(-1.5,2.7)$ & $2.9(-1,7.0)$ & $9.2(1.4,17.7)^{* *}$ \\
BMI $\geq 25$ & $4.5(-0.3,9.5)^{*}$ & $-0.02(-1.1,1.1)$ & $-0.8(-2.2,0.7)$ & $-1.3(-3.3,0.8)$ & $3.3(-0.9,7.6)$ \\
Peri-menopausal & $1.8(-4.4,8.4)$ & $-0.1(-1.4,1.3)$ & $-1.4(-2.9,0.2)^{*}$ & $0.05(-2.4,2.5)$ & $7.5(2.2,13.2)^{* * *}$ \\
Post-menopausal & $3.6(-2.8,10.5)$ & $-0.02(-1.1,1.1)$ & $0.1(-1.9,2.2)$ & $0.3(-2.8,3.6)$ & $1.4(-4.5,7.7)$ \\
$\leq$ High school & $5.8(-2.7,15)$ & $1.2(-0.7,3.2)$ & $-2.4(-4.7,-0.1)^{* *}$ & $0.9(-2.6,4.5)$ & $7.6(0.6,15.1)^{* *}$ \\
Some college or more & $3.8(-1.1,8.9)$ & $-0.9(-1.9,0.2)$ & $0.05(-1.3,1.4)$ & $0.3(-1.8,2.5)$ & $1.1(-3.2,5.6)$ \\
Low alcohol consumption & $8.8(2.7,15.3)^{* * *}$ & $0.6(-0.7,1.8)$ & $-1.4(-3.0,0.2)^{*}$ & $1.3(-1.2,3.9)$ & $7.5(2.3,13.0)^{* * *}$ \\
Medium/high alcohol & $-0.2(-6.1,6.0)$ & $-1.2(-2.5,0.2)^{*}$ & $0.5(-1.2,2.2)$ & $-0.9(-3.6,1.8)$ & $3.9(-1.4,9.5)$ \\
Consumption & & & & & \\
\hline
\end{tabular}

${ }^{a}$ Results shown are as percent change in biomarker level per an interquartile increase in exposure, which is $4 \mu \mathrm{g} / \mathrm{m}^{3}$ for $\mathrm{PM} \mathrm{M}_{10-2.5}$. Analyses were based on logtransformed biomarker levels, *adjusted for study site, age (continuous), race/ethnicity, education, menopausal status, BMI, active smoking status, alcohol category. Stratifying variables were omitted from respective models. ${ }^{*} p<0.10 ;{ }^{* *} p<0.05 ;{ }^{* *} p<0.01$ 


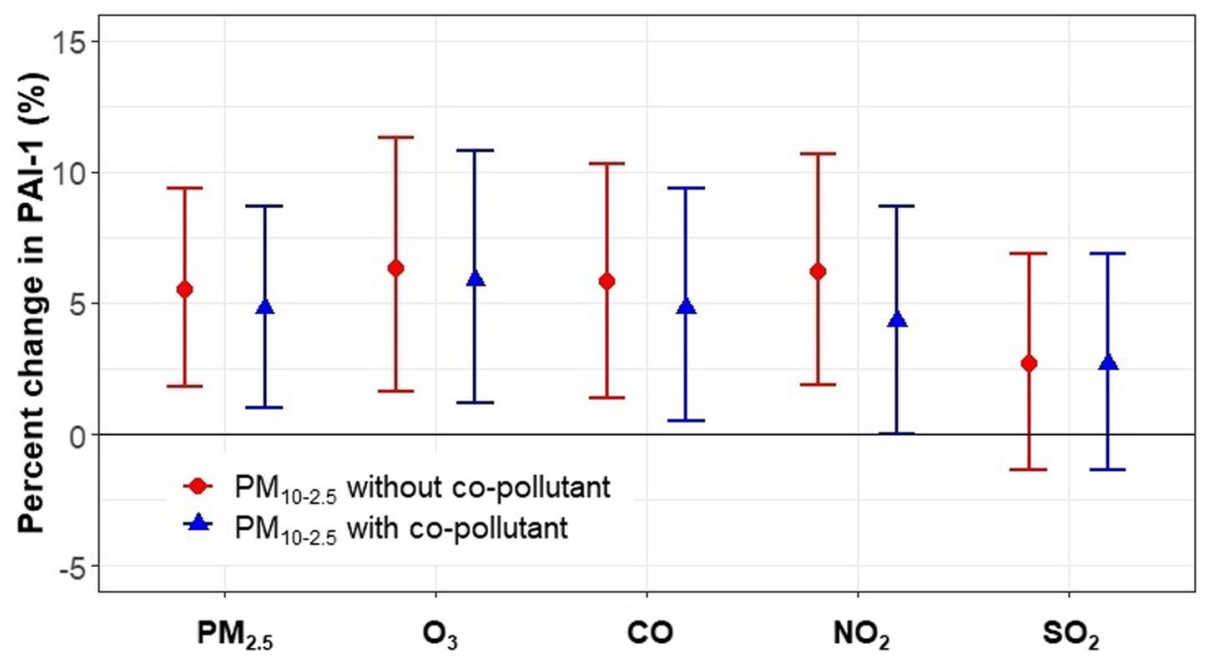

Fig. 1 Associations between $\mathrm{PM}_{10-2.5}$ and PAl-1, without (dot symbol) and with (triangle symbol) $\mathrm{PM}_{2.5}, \mathrm{O}, \mathrm{CO}, \mathrm{NO}_{2}$, and $\mathrm{SO}_{2}$ adjusted in the

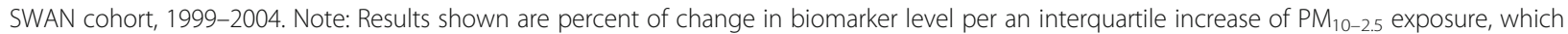
is $4 \mu \mathrm{g} / \mathrm{m}^{3}$. Analyses were based on log-transformed biomarker levels, adjusted for study site, age (continuous), race/ethnicity, education, menopausal status, BMI, active smoking status, alcohol consumption category. For each co-pollutant, analyses were run in the subset with nonmissing values for both $\mathrm{PM}_{10-2.5}$ and the co-pollutant

Similarly, PAI-1 increased by $4.8 \%(0.5,9.4 \%)$ per $4 \mu \mathrm{g} /$ $\mathrm{m}^{3}$ increase in $\mathrm{PM}_{10-2.5}$ after adjustment for coexposure to $\mathrm{CO}$, and by $4.3 \%(0,8.7 \%)$ per $4 \mu \mathrm{g} / \mathrm{m}^{3}$ increase in $\mathrm{PM}_{10-2.5}$ independent of exposure to $\mathrm{NO}_{2}$. Confounding by $\mathrm{SO}_{2}$ cannot be evaluated, because in the subset of data with matched $\mathrm{SO}_{2}$ measurements, $\mathrm{PM}_{10-}$ 2.5 showed no association with PAI-1 regardless of including $\mathrm{SO}_{2}$ or not. The availability of $\mathrm{SO}_{2}$ measurements may have introduced bias for testing the association between $\mathrm{PM}_{10-2.5}$ and PAI-1.

\section{Discussion}

This study provided new evidence for associations between long-term exposure to coarse particles and CVD markers. Specifically, we found that prior one-year $\mathrm{PM}_{10-2.5}$ exposure levels were positively associated with the levels of PAI-1, and marginally positively associated with hs-CRP. Elevated PAI-1 increases the risk of thrombosis by inhibiting tPA activity, which initiates the fibrinolysis processes that break down excess blood clotting. Therefore, the associations we found suggested that elevated long-term exposure to coarse particles may increase the risk of thrombosis.

As mentioned earlier, very few studies were conducted on the associations of long-term exposure to $\mathrm{PM}_{10-2.5}$ with CVD markers. Chen and Schwarz observed increased white blood cell count, a potential inflammatory marker, was associated with one-year local $\mathrm{PM}_{10}$ levels (ranging 14.6-78.5 $\mu \mathrm{g} / \mathrm{m}^{3}$ ) in the US [24]. In contrast, in England, Forbes et al. reported no associations between inflammatory markers, fibrinogen or hs-CRP, and chronic exposures to several outdoor pollutants, including $\mathrm{PM}_{10}$ (ranging 11.0$36.1 \mu \mathrm{g} / \mathrm{m}^{3}$ ) [25]. Inconsistencies in study findings could have resulted from differences in air pollutant ranges, geographic and temporal differences in the composition of particles, and/or population differences. The Multi-Ethnic Study of Atherosclerosis estimated 5-year average $\mathrm{PM}_{10-2.5}$ exposures between 2000 and 2006 varied by individuals, with a mean of $5.0 \pm 1.7 \mu \mathrm{g} / \mathrm{m}^{3}$, and found positive, though not statistically significant, associations between long-term $\mathrm{PM}_{10-2.5}$ concentrations and inflammation and coagulation markers [16]. The authors further identified that endotoxin and copper in $\mathrm{PM}_{10-2.5}$ contributed most to inflammation and coagulation effects, respectively, which were robust to the adjustment for $\mathrm{PM}_{2.5}$. As an indicator of abrasive brake wear, copper is expected in substantial amount in $\mathrm{PM}_{10-2.5}$ at most of the SWAN sites, which are major metropolitan areas with intense traffic flow, particularly in Los Angeles [26]. Our study echoes Adar et al's findings, providing additional evidence on the impact of $\mathrm{PM}_{10-2.5}$ coagulation among different locations and populations.

Our previous studies have identified associations between exposures to $\mathrm{PM}_{2.5}$ and ambient gases with inflammatory and hemostatic markers in the SWAN cohort. One-year exposure to $\mathrm{PM}_{2.5}$ was associated with increases in hs-CRP (\% of change [95th\% confidence interval]: $21 \%$ [6.6, 37\%]) and PAI-1 (35\% [19, 53\%]) per $10 \mu \mathrm{g} / \mathrm{m}^{3}$ increase in $\mathrm{PM}_{2.5}$ concentrations [18]. Oneyear exposure to $\mathrm{CO}$ and $\mathrm{NO}_{2}$ were also positively associated with PAI-1, though not statistically significant [19]. We note that, while the increased inflammation and 
coagulation tendency associated with $\mathrm{PM}_{10-2.5}$ was similar to that from $\mathrm{PM}_{2.5}, \mathrm{PM}_{10-2.5}$ exposure was weakly correlated with $\mathrm{PM}_{2.5}$, regardless of whether long-term (Spearman $\mathrm{r}=0.30, p<0.01)$ or short-term $(r=0.15, p<0.01)$ exposure. The two-pollutant analyses confirmed the associations with $\mathrm{PM}_{2.5}$ and ambient gases, and further demonstrated that $\mathrm{PM}_{10-2.5}$ created additional burden on inflammation and coagulation. The previous studies did not control for $\mathrm{PM}_{10-2.5}$, so some of the associations observed may have been due to confounding by $\mathrm{PM}_{10-2.5}$.

Considering the variations in chemical composition and the deposition locations within the lungs associated with their sizes, we expect that $\mathrm{PM}_{10-2.5}$ cause health effects through mechanisms different from those of $\mathrm{PM}_{2.5}$. However, it has been observed that coarse PM of low density, such as soil particles, have deposited deeper in the lung as well [27], suggesting that they could cause potential health impacts beyond size alone. A study using in vitro models found out that $\mathrm{PM}_{2.5}$ and $\mathrm{PM}_{10-2.5}$ affected nasal and bronchial epithelial cells and immune response differently, but both increased release of IL-6 in bronchial epithelial cells [28]. Ljubimova et al. observed up regulation of genes encoding inflammatory cytokine pathways (IL13-R $\alpha 1$ and IL-16) in the brains of rats exposed to $\mathrm{PM}_{10-2.5}$ sourced from the Los Angeles Basin for 1 month, and found that $\mathrm{PM}_{10-2.5}$ was the only particles contributing to this process [29]. A few toxicological studies has indicated that $\mathrm{PM}_{10-2.5}$ may have stronger associations with inflammation and coagulation than $\mathrm{PM}_{2.5}$ [30-34].

Furthermore, risks derived from short-term and longterm exposure may be generated through different mechanisms. Coagulation activation, indicated by the increase of PAI-1 level, is a typical risk that has been associated with long-term exposure [35]. Two potential mechanisms could explain the increased PAI-1. One possibility is that, some $\mathrm{PM}_{10-2.5}$ particles travel deeper in the lung and cause systemic inflammation and oxidative stress similar to that from $\mathrm{PM}_{2.5}$. Generated by the endothelium, PAI-1 is activated by chronic inflammatory conditions and endothelium injury to inhibit fibrinolysis, the process that degrades blood clots; in other words, PAI-1 allows blood clot formation and shortens bleeding time. Another possible pathway is that $\mathrm{PM}_{10-2.5}$ induces respiratory tract inflammation. Inflammatory cytokines produced in the respiratory tract can potentially enter the circulatory system where they can stimulate the liver to release coagulation factors that can alter hemostasis [4]. This could be a "false" coagulation signal that is not accompanied by systemic inflammation or blood vessel damage that initiates fibrinolysis, eventually increasing the potential for thrombosis. Under such circumstances, there may not be clear signs of systemic inflammation and/or endothelium injury. Overall, evidence from epidemiologic or toxicological studies is limited for systemic inflammation and altered hemostasis associated with the long-term exposure to $\mathrm{PM}_{10-2.5}$. Given the marginal/unstable association with hs-CRP and absent relationship with fibrinogen and factor VIIc, we cannot conclude whether inflammation and thrombosis were from the same biological process, or differentiate whether such coagulation reflected vascular inflammation or deep vein thrombosis. Future studies are warranted to explore the physiological consequences and mechanisms involved with chronic exposure to $\mathrm{PM}_{10-2.5}$, especially to the specific chemical species of $\mathrm{PM}_{10-2.5}$.

Our findings also suggest that the associations between PAI-1 and one-year PM $_{10-2.5}$ exposure appeared particularly strong in some subgroups, including women with a $\mathrm{BMI}<25$, women who were peri-menopausal, women with equivalent or less than a high school education, and women who reported low alcohol consumption. That is to say, apart from toxicity of chemicals, physiological condition, i.e., BMI and menopausal status, and socioeconomic background, i.e., education, could influence vulnerability to external exposures. For women, the menopausal transition is a complex and multifaceted process that involves multiple organ systems and genetic variability where physiological impacts can manifest differently among individual women [17]. Being in midlife and experiencing a transition through menopause potentially increases women's vulnerability to environmental exposures, such as air pollution.

This study had several strengths. First, SWAN is a large, multi-site, longitudinal study, which provided coverage of a wide range of ambient exposure levels and particle compositions associated with local sources. Also, with the same participants followed longitudinally and the same sampling/analytical approaches for measurement of biomarkers consistently used, our data provided a unique opportunity to examine health effects associated with long-term $\mathrm{PM}_{10-2.5}$ exposure. Second, because residential history has been maintained for each SWAN participant, we were able to use ambient monitoring data, along with residential history, to assign exposure levels to participants. Finally, substantial demographic and health information collected in SWAN allowed us to examine the impact of effect modifiers, including timevarying menopausal status for this midlife population.

Meanwhile, the limitations of estimating $\mathrm{PM}_{10-2.5}$ exposure need to be noted when interpreting our results. $\mathrm{PM}_{10-2.5}$ was not routinely measured directly, its level was either calculated through the ambient monitor concentrations of $\mathrm{PM}_{10}$ and $\mathrm{PM}_{2.5}$ as we did, or obtained by modeling. Some studies used estimations from land use regression models, which were based on limited cross-sectional measurements to simulate long-term spatial variation $[14,16]$. The 5 -year average $\mathrm{PM}_{10-2.5}$ 
exposures of the Multi-Ethnic Study of Atherosclerosis cohort were estimated using land use regression model, ranging from $3.8 \pm 1.3 \mu \mathrm{g} / \mathrm{m}^{3}$ in Winston-Salem, North Carolina to $5.6 \pm 1.2 \mu \mathrm{g} / \mathrm{m}^{3}$ in Chicago, Illinois [16]. Models based on satellite data are not applicable to this study, as most satellite data are only available after early 2000, and therefore, would not cover a significant amount of SWAN visits around 2000. Furthermore, $\mathrm{PM}_{10-2.5}$ concentrations were not commonly estimated through satellite data in the USA, as $\mathrm{PM}_{2.5}$ has been the primary focus. We acknowledge that $\mathrm{PM}_{10-2.5}$ concentration tends to be more heterogeneous across space than $\mathrm{PM}_{2.5}$, resulting in great uncertainty for $\mathrm{PM}_{10-2.5}$ estimations through nearby stationary monitors within a $20 \mathrm{~km}$ buffer. The assigned exposure may be overestimated or underestimated depending on whether there are sources nearby. We assume that the exposure assignment error tends to be non-differential [36]. Additionally, in this study, we calculated $\mathrm{PM}_{10-2.5}$ concentrations using data obtained from co-located $\mathrm{PM}_{10}$ and $\mathrm{PM}_{2.5}$ monitors to avoid potential bias. However, $\mathrm{PM}_{10}$ monitoring had been greatly reduced (typically every 6 days for $\mathrm{PM}_{10}$, compared to typically every 3 days for $\mathrm{PM}_{2.5}$ ), which limited the ability to calculate $\mathrm{PM}_{10-2.5}$ data. This was a particular concern for the Los Angeles site, where only $24 \%$ of women had matched $\mathrm{PM}_{10-2.5}$ measurements. The mean average one-year $\mathrm{PM}_{10-2.5}$ exposure in our study ranged from $8.5 \pm 3.8 \mu \mathrm{g} / \mathrm{m}^{3}$ to $17.5 \pm 2.3 \mu \mathrm{g} / \mathrm{m}^{3}$ at different sites, which aligned with the levels reported in the literature.

A few other limitations also need to be considered. First, as a common issue in cohort studies, loss of follow-up was also observed in SWAN, which reduced statistical power. In our dataset, $35 \%$ of participants had completed one or two visits only, including almost all participants at Newark site and half of the participants at Los Angeles site, which was equivalent to $20 \%$ of visits. We were not able to run the regression model within these subjects because of the small sample size; however, sensitivity tests excluding these participants confirmed the associations we observed (Table S2), including those from stratified analyses (not shown). Second, potential confounding factors, such as, noise, greenness, household income, were not included in this analysis due to limited available data. Future studies are recommended to include them into considerations. Lastly, heterogeneity of $\mathrm{PM}_{10-2.5}$ compositions by study location may influence the associations with biomarkers, but composition information was not available to use in our study.

\section{Conclusions}

The results of this study support the hypothesis that long-term exposure to coarse particulate matter may contribute to inflammation and thrombosis, markers of CVD. The observed associations between long-term $\mathrm{PM}_{10-2.5}$ exposure and PAI-1 were independent, as they were not confounded by ambient $\mathrm{PM}_{2.5}$, ozone, $\mathrm{NO}_{2}$, or CO. Particular subgroups were more sensitive to $\mathrm{PM}_{10-}$ 2.5 exposure. Further epidemiological and toxicological studies are warranted to identify the specific mechanisms of how $\mathrm{PM}_{10-2.5}$ may affect these biomarkers.

\section{Supplementary information}

The online version contains supplementary material available at https://doi. org/10.1186/s12940-020-00663-1.

Additional file 1: Table S1. Distribution of prior one-year average $\mathrm{PM}_{2.5}$, ozone, $\mathrm{CO}, \mathrm{NO}_{2}$, and $\mathrm{SO}_{2}$ concentrations by SWAN site, 1999-2004. Table S2. Results of sensitivity test for the associations between PM $_{10-2.5}$ and cardiovascular disease markers based on several models for SWAN cohort, 1999-2004. Table S3. Adjusted associations between $\mathrm{PM}_{10-2.5}$ and $\mathrm{PM}_{2.5}$, Ozone, $\mathrm{CO}, \mathrm{NO}_{2}, \mathrm{SO}_{2}$ and cardiovascular disease markers for SWAN cohort, 1999-2004. (docx 29 kb)

\section{Abbreviations}

CVD: Cardiovascular disease; $\mathrm{PM}_{2.5}$ : Fine particulate matter; $\mathrm{PM}_{10-2.5}$ : Coarse particulate matter; SWAN: Study of Women's Health Across the Nation; US EPA: United States Environmental Protection Agency; hs-CRP: High sensitivity C-reactive protein; factor VIIc: Factor VII coagulant; tPA-ag: Tissue-type plasminogen activator antigen; PAI-1: Plasminogen activator inhibitor Type 1; ELISA: Enzyme-linked immunosorbent assay; $\mathrm{O}_{3}$ : Ozone; $\mathrm{CO}$ : Carbon monoxide; $\mathrm{NO}_{2}$ : Nitrogen dioxide; $\mathrm{SO}_{2}$ : Sulfur dioxide; $\mathrm{BMI}$ : Body mass index; AIC: Akaike Information Criterion; ZCTA: ZIP code tabulation area

\section{Acknowledgements}

The Study of Women's Health Across the Nation (SWAN) has grant support from the National Institutes of Health $(\mathrm{NIH})$, DHHS, through the National Institute on Aging (NIA), the National Institute of Nursing Research (NINR) and the NIH Office of Research on Women's Health (ORWH) (Grants U01NR004061; U01AG012505, U01AG012535, U01AG012531, U01AG012539, U01AG012546, U01AG012553, U01AG012554, U01AG012495). The content of this manuscript is solely the responsibility of the authors and does not necessarily represent the official views of the NIA, NINR, ORWH or the NIH. The SWAN Repository (U01AG017719).

This publication was supported in part by the National Center for Research Resources and the National Center for Advancing Translational Sciences, National Institutes of Health, through UCSF-CTSI Grant Number UL1 RR024131. Support for address geocoding was provided by California Institute for Energy and Environment, University of California (Subaward No. POB228-X86).

Clinical Centers: University of Michigan, Ann Arbor - Siobán Harlow, PI 2011 present, MaryFran Sowers, PI 1994-2011; Massachusetts General Hospital, Boston, MA - Joel Finkelstein, PI 1999 - present; Robert Neer, PI 1994-1999; Rush University, Rush University Medical Center, Chicago, IL - Howard Kravitz, PI 2009 - present; Lynda Powell, PI 1994-2009; University of California, Davis/Kaiser - Ellen Gold, Pl; University of California, Los Angeles - Gail Greendale, Pl; Albert Einstein College of Medicine, Bronx, NY - Carol Derby, PI 2011 - present, Rachel Wildman, PI 2010-2011; Nanette Santoro, PI 2004-2010; University of Medicine and Dentistry - New Jersey Medical School, Newark - Gerson Weiss, PI 19942004; and the University of Pittsburgh, Pittsburgh, PA - Karen Matthews, PI. $\mathrm{NIH}$ Program Office: National Institute on Aging, Bethesda, MD - Chhanda Dutta 2016- present; Winifred Rossi 2012-2016; Sherry Sherman 1994-2012; Marcia Ory 1994-2001; National Institute of Nursing Research, Bethesda, MD Program Officers.

Central Laboratory: University of Michigan, Ann Arbor - Daniel McConnell (Central Ligand Assay Satellite Services).

SWAN Repository: University of Michigan, Ann Arbor - Siobán Harlow 2013 Present; Dan McConnell 2011-2013; MaryFran Sowers 2000-2011. 
Coordinating Center: University of Pittsburgh, Pittsburgh, PA - Maria Mori Brooks, PI 2012 - present; Kim Sutton-Tyrrell, PI 2001-2012; New England Research Institutes, Watertown, MA - Sonja McKinlay, PI 1995-2001. Steering Committee: Susan Johnson, Current Chair.

Chris Gallagher, Former Chair.

We thank the study staff at each site and all the women who participated in SWAN.

The authors also want to thank Ms. Dharshani Pearson for reviewing the manuscript and providing valuable input.

The content of this manuscript is solely the responsibility of the authors and does not necessarily represent the official views of the Office of Environmental Health Hazard Assessment, California Environmental Protection Agency, or the State of California.

\section{Authors' contributions}

ED conducted data analysis and prepared the first draft. BM and RBroadwin helped with the conception of the hypothese and prepared datasets. KE and RBasu provided key input for refining analysis and manuscript. EG, CD, and SP were the PIs of individual SWAN sites, and supervised the data collection at their sites. XW oversaw the whole study, including proposed the hypothesis, designed data analysis plan, supervised the data analysis, conducted results validation, and developed the manuscript based on the first draft. All authors helped with reviewing and finalizing this manuscript. All authors read and approved the final manuscript.

\section{Availability of data and materials}

The data that support the findings of this study are available from California Office of Statewide Health Planning and Development (OSHPD) but restrictions apply to the availability of these data, which were used under license for the current study, and so are not publicly available. Data are however available from the authors upon reasonable request and with permission of OSHPD.

\section{Ethics approval and consent to participate}

The SWAN protocols and this study of air pollution were approved by the Institutional Review Boards at all six participating sites, and all participants provided signed, written informed consent for the SWAN protocols at study recruitment.

\section{Consent for publication}

Not applicable.

\section{Competing interests}

The authors declare that they have no competing interests.

\section{Author details}

${ }^{1}$ Air and Climate Epidemiology Section, Office of Environmental Health Hazard Assessment, California Environmental Protection Agency, 1515 Clay Street, 16th Floor, Oakland, CA 94612, USA. ²Department of Environmental Health Sciences, Yale School of Public Health, Yale University, New Haven, $C T$, USA. ${ }^{3}$ Department of Public Health Sciences, School of Medicine, University of California, Davis, CA, USA. ${ }^{4}$ Department of Neurology, and of Epidemiology and Population Health, Albert Einstein College of Medicine, Bronx, NY, USA. ${ }^{5}$ Departments of Epidemiology and Environmental Health Sciences, School of of Public Health, University of Michigan, Ann Arbor, MI, USA.

\section{Received: 23 March 2020 Accepted: 12 October 2020}

\section{Published online: 05 November 2020}

\section{References}

1. Garcia M, Mulvagh SL, Merz CN, Buring JE, Manson JE. Cardiovascular disease in women: clinical perspectives. Circ Res. 2016;118(8):1273-93.

2. Particle Pollution and Cardiovascular Effects [https://www.epa.gov/ pmcourse/particle-pollution-and-cardiovascular-effects\#intro].

3. Brook RD, Rajagopalan S, Pope CA 3rd, Brook JR, Bhatnagar A, Diez-Roux AV, et al. Particulate matter air pollution and cardiovascular disease: an update to the scientific statement from the American Heart Association. Circulation. 2010;121(21):2331-78.
4. USEPA. Integrated Science Assessment (ISA) for Particulate Matter (Final Report, 2019). Washington, DC, EPA/600/R-19/188: U.S. Environmental Protection Agency; 2019.

5. Pakkanen TA, Loukkola K, Korhonen CH, Aurela M, Mäkelä T, Hillamo RE, et al. Sources and chemical composition of atmospheric fine and coarse particles in the Helsinki area. Atmos Environ. 2001;35(32):5381-91.

6. Chen YC, Weng YH, Chiu YW, Yang CY. Short-term effects of coarse particulate matter on hospital admissions for cardiovascular diseases: a casecrossover study in a Tropical City. J Toxicol Environ Health A. 2015;78(19): 1241-53.

7. Lee H, Honda Y, Hashizume M, Guo YL, Wu CF, Kan H, et al. Short-term exposure to fine and coarse particles and mortality: a multicity time-series study in East Asia. Environ Pollut. 2015;207:43-51.

8. Malig BJ, Green S, Basu R, Broadwin R. Coarse particles and respiratory emergency department visits in California. Am J Epidemiol. 2013;178(1):58-69.

9. Powell H, Krall JR, Wang Y, Bell ML, Peng RD. Ambient coarse particulate matter and hospital admissions in the Medicare cohort air pollution study, 1999-2010. Environ Health Perspect. 2015;123(11):1152-8.

10. Yorifuji T, Kashima S, Doi H. Associations of acute exposure to fine and coarse particulate matter and mortality among older people in Tokyo, Japan. Sci Total Environ. 2016;542(Pt A):354-9.

11. Zhao $Y$, Wang S, Lang L, Huang C, Ma W, Lin H. Ambient fine and coarse particulate matter pollution and respiratory morbidity in Dongguan, China. Environ Pollut. 2017;222:126-31.

12. Adar SD, Filigrana PA, Clements N, Peel JL. Ambient coarse particulate matter and human health: a systematic review and meta-analysis. Curr Environ Health Rep. 2014;1:258-74.

13. Brunekreef $B$, Forsberg B. Epidemiological evidence of effects of coarse airborne particles on health. Eur Respir J. 2005;26(2):309-18.

14. D'Souza JC, Kawut SM, Elkayam LR, Sheppard L, Thorne PS, Jacobs DR Jr, et al. Ambient coarse particulate matter and the right ventricle: the multiethnic study of atherosclerosis. Environ Health Perspect. 2017;125(7):077019.

15. Honda T, Eliot MN, Eaton CB, Whitsel E, Stewart JD, Mu L, et al. Long-term exposure to residential ambient fine and coarse particulate matter and incident hypertension in post-menopausal women. Environ Int. 2017;105:79-85.

16. Adar SD, D'Souza J, Mendelsohn-Victor K, Jacobs DR, Cushman M, Sheppard $L$, et al. Markers of inflammation and coagulation after long-term exposure to coarse particulate matter: a cross-sectional analysis from the multi-ethnic study of atherosclerosis. Environ Health Perspect. 2015;123(6):541-8.

17. Sowers M, Crawford S, Sternfeld B, Morganstein D, Gold E, Greendale G, et al. SWAN: A Multicenter, Multiethnic, Community-Based Cohort Study of Women and the Menopausal Transition. In: JK RAL, Marcus R, editors. Menopause: Biology and Pathobiology. San Diego: Academic Press; 2000. p. 175-88.

18. Green R, Broadwin R, Malig B, Basu R, Gold EB, Qi L, et al. Long- and shortterm exposure to air pollution and inflammatory/hemostatic markers in midlife women. Epidemiology. 2016;27(2):211-20.

19. Wu XM, Basu R, Malig B, Broadwin R, Ebisu K, Gold EB, Qi L, Derby C, Green RS. Association between gaseous air pollutants and inflammatory, hemostatic and lipid markers in a cohort of midlife women. Environ Int. 2017;107:131-9.

20. Wang NC, Matthews KA, Barinas-Mitchell EJM, Chang C-CH, El Khoudary SR. Inflammatory/hemostatic biomarkers and coronary artery calcification in midlife women of African-American and white race/ethnicity: the study of Women's health across the nation (SWAN) heart study. Menopause. 2016; 23(6):653-61.

21. Chandler WL, Alessi MC, Aillaud MF, Henderson P, Vague P, Juhan-Vague I. Clearance of tissue plasminogen activator (TPA) and TPA/plasminogen activator inhibitor type 1 (PAI-1) complex: relationship to elevated TPA antigen in patients with high PAl-1 activity levels. Circulation. 1997;96(3):761-8.

22. Declerck PJ, Alessi MC, Verstreken M, Kruithof EK, Juhan-Vague I, Collen D. Measurement of plasminogen activator inhibitor 1 in biologic fluids with a murine monoclonal antibody-based enzyme-linked immunosorbent assay. Blood. 1988;71(1):220-5.

23. Derby CA, Crawford SL, Pasternak RC, Sowers M, Sternfeld B, Matthews KA. Lipid changes during the menopause transition in relation to age and weight: the study of Women's health across the nation. Am J Epidemiol. 2009;169(11):1352-61.

24. Chen JC, Schwartz J. Metabolic syndrome and inflammatory responses to long-term particulate air pollutants. Environ Health Perspect. 2008;116(5):612-7.

25. Forbes LJ, Patel MD, Rudnicka AR, Cook DG, Bush T, Stedman JR, Whincup $\mathrm{PH}$, Strachan DP, Anderson RH. Chronic exposure to outdoor air pollution and markers of systemic inflammation. Epidemiology. 2009;20(2):245-53. 
26. Pakbin P, Ning Z, Shafer MM, Schauer JJ, Sioutas C. Seasonal and spatial coarse particle elemental concentrations in the Los Angeles area. Aerosol Sci Technol. 2011;45(8):949-63.

27. Deng Q, Deng L, Miao Y, Guo X, Li Y. Particle deposition in the human lung: health implications of particulate matter from different sources. Environ Res. 2019;169:237-45

28. Onishi T, Honda A, Tanaka M, Chowdhury PH, Okano H, Okuda T, et al. Ambient fine and coarse particles in Japan affect nasal and bronchial epithelial cells differently and elicit varying immune response. Environ Pollut. 2018;242:1693-701.

29. Ljubimova JY, Braubach O, Patil R, Chiechi A, Tang J, Galstyan A, et al. Coarse particulate matter (PM2.5-10) in Los Angeles Basin air induces expression of inflammation and cancer biomarkers in rat brains. Sci Rep. 2018;8(1):5708

30. Alexis NE, Lay JC, Zeman K, Bennett WE, Peden DB, Soukup JM, Devlin RB, Becker S. Biological material on inhaled coarse fraction particulate matter activates airway phagocytes in vivo in healthy volunteers. J Allergy Clin Immunol. 2006;117(6):1396-403.

31. Happo MS, Salonen RO, Halinen Al, Jalava PI, Pennanen AS, Dormans JA, et al. Inflammation and tissue damage in mouse lung by single and repeated dosing of urban air coarse and fine particles collected from six European cities. Inhal Toxicol. 2010;22(5):402-16.

32. Kleinman MT, Sioutas C, Chang MC, Boere AJ, Cassee FR. Ambient fine and coarse particle suppression of alveolar macrophage functions. Toxicol Lett. 2003;137(3):151-8.

33. Monn C, Becker S. Cytotoxicity and induction of proinflammatory cytokines from human monocytes exposed to fine (PM2.5) and coarse particles (PM10-2. 5) in outdoor and indoor air. Toxicol Appl Pharmacol. 1999;155(3):245-52.

34. Schins RP, Lightbody JH, Borm PJ, Shi T, Donaldson K, Stone V. Inflammatory effects of coarse and fine particulate matter in relation to chemical and biological constituents. Toxicol Appl Pharmacol. 2004;195(1):1-11.

35. Cesari M, Pahor M, Incalzi RA. Plasminogen activator inhibitor-1 (PAl-1): a key factor linking fibrinolysis and age-related subclinical and clinical conditions. Cardiovasc Ther. 2010;28(5):e72-91.

36. Wilson WE, Suh HH. Fine particles and coarse particles: concentration relationships relevant to epidemiologic studies. J Air Waste Manag Assoc. 1997;47(12):1238-49.

\section{Publisher's Note}

Springer Nature remains neutral with regard to jurisdictional claims in published maps and institutional affiliations.

Ready to submit your research? Choose BMC and benefit from:

- fast, convenient online submission

- thorough peer review by experienced researchers in your field

- rapid publication on acceptance

- support for research data, including large and complex data types

- gold Open Access which fosters wider collaboration and increased citations

- maximum visibility for your research: over $100 \mathrm{M}$ website views per year

At BMC, research is always in progress.

Learn more biomedcentral.com/submissions 